\title{
A Utilização do Software Luz do Saber como Ferramenta de Apoio ao Processo de Desenvolvimento da Leitura e Escrita
}

\author{
Lucimara Cruz de Souza $^{1}$, Almir de Oliveira Costa Junior ${ }^{1}$ \\ ${ }^{1}$ Licenciatura em Computação - Escola Superior de Tecnologia - Universidade do Estado \\ do Amazonas (UEA) - Manaus - AM - Brazil \\ \{lcs.inf, adjunior\}@uea.edu.br
}

\begin{abstract}
This article presents an experience report on the process of planning and applying a didactic sequence, using the luz do saber software in the process of developing reading and writing skills with students in the $3 r d$ year of elementary school. The results found show a significant improvement in the formation of words and syllables.
\end{abstract}

Resumo. Este artigo apresenta um relato de experiência sobre o processo de planejamento e aplicação de uma sequência didática, utilizando o software luz do saber no processo de desenvolvimento de habilidades da leitura e escrita com alunos do $3^{\circ}$ ano do Ensino Fundamental. Os resultados encontrados apresentam evidências de uma melhora significativa na formação de sílabas e palavras.

\section{Introdução}

O domínio das habilidades de leitura e escrita tem sido um dos grandes desafios do desenvolvimento infantil, pois sua aquisição nas séries iniciais é determinante para o posterior sucesso acadêmico ao longo da educação básica.

Estudos discutem que crianças com dificuldades em habilidades iniciais de leitura, tendem a ter trajetórias de insucesso escolar com consequências de curto a longo prazo que, afetam o indivíduo, a sociedade e a economia. Aprender a ler e a escrever são processos complexos, que demandam outros componentes, como a linguagem oral e habilidades preliminares de leitura e escrita, entre outros. [Pazeto, León and Seabra 2017].

Diante dessa perspectiva, este trabalho apresenta um relato de experiência sobre o processo de planejamento e aplicação de uma sequência didática utilizando o software Luz do Saber para auxiliar no processo de desenvolvimento da leitura e escrita de alunos do $3^{\circ}$ ano do Ensino Fundamental I.

Para relatar esta experiência, o artigo foi organizado como segue: Recursos e estratégias na Seção 2. Aplicação da sequência didática na Seção 3. Resultados e Discussões são apresentados na Seção 4. Por fim, as considerações finais na Seção 5.

\section{Recursos e Estratégias Metodológicas}

Nesta seção, serão apresentados o planejamento da sequência didática e as estratégias utilizadas durante a aplicação.

\subsection{O software Luz do Saber}

O Luz do Saber é uma ferramenta pedagógica que tem como objetivo auxiliar crianças em processo de alfabetização, desenvolvendo as habilidades e competências da leitura e escrita. Este software foi criado em 2009 no Estado do Ceará e teve como autores os educadores Márcia Campos, Marcos Nascimento e Thiago Oliveira, em parceria com a Secretaria de 
Educação do Estado do Ceará. O software está disponível para os sistemas operacionais Windows ou Linux, podendo também ser executado em uma versão online para navegadores.

\subsection{O Planejamento da Sequência Didática}

Para realizar o planejamento e organização das atividades relatadas neste trabalho, foram utilizados alguns princípios básicos do alinhamento construtivo, tais como: i - Atividades de Ensino (A.E.), ii - Atividades de Aprendizagem (A.A.) e iii - Resultados Pretendidos na Aprendizagem (RPAs) [Biggs and Tag 2011].

Além disso, foi levado em consideração a organização das atividades com base em uma sequência didática. Para [Oliveira 2013] trata-se de um procedimento simples que compreende um conjunto de atividades conectadas entre si, e, prescinde de um planejamento para delimitação de cada etapa e/ ou atividades para trabalhar os conteúdos disciplinares de forma integrada para uma melhor dinâmica no processo ensino aprendizagem". Na Figura 1 é apresentado um fluxograma com a visão geral da organização da sequência didática.

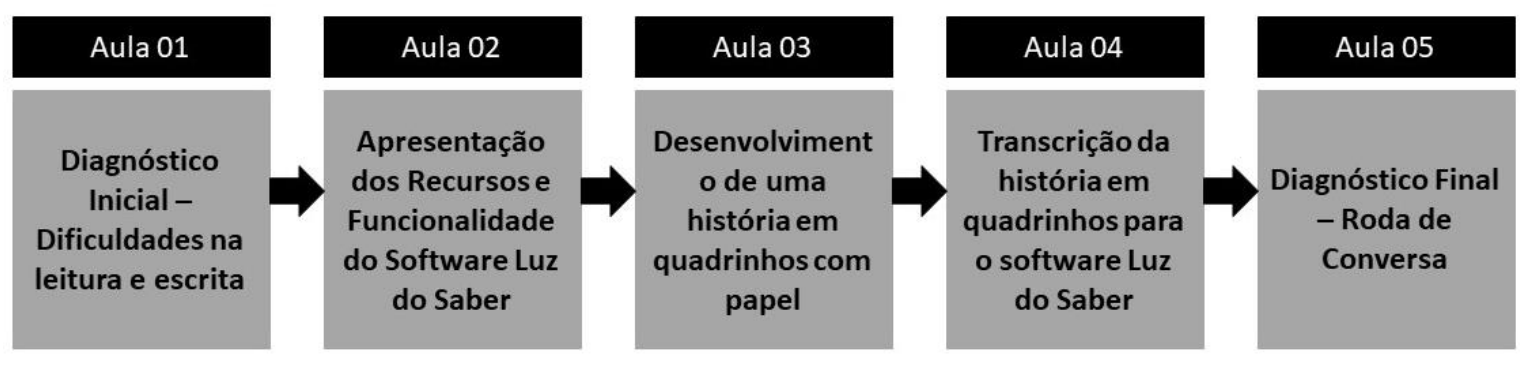

Figura 1. Fluxograma representando a visão Geral da sequência didática

\subsection{Caracterização do público-alvo}

De modo geral, as atividades descritas neste trabalho, foram aplicadas em uma turma de $3^{\circ}$ ano do Ensino Fundamental I de uma escola pública do município de Manaus. A turma era composta por 11 meninos e 13 meninas, totalizando 24 alunos. No período de aplicação das atividades, estes alunos possuíam idade variando em 9 e 10 anos.

\section{Aplicação da Sequência Didática}

\subsection{Aplicação da aula 1 - Diagnóstico inicial}

O objetivo principal desta aula, era realizar um diagnóstico inicial para identificar os níveis de dificuldades dos alunos em relação à leitura e escrita.

Neste sentido, para esta aula foram definidos: A. E. 01 - Ler e explicar sobre o exercício do diagnóstico e A. A. 01 - Desenvolver exercício de diagnóstico. Inicialmente, a professora propôs um diagnóstico com dois exercícios. Na figura 2a é possível observar o exemplo de um dos exercícios utilizados. Na figura $2 \mathrm{~b}$ é ilustrado a professora explicando o diagnóstico inicial. De modo geral, as atividades propostas para esta aula foram desenvolvidas em 40 minutos. 


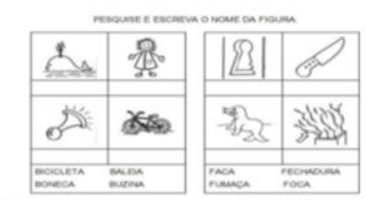

(a) Exemplo de exercicio utilizado no diagnóstico inicial

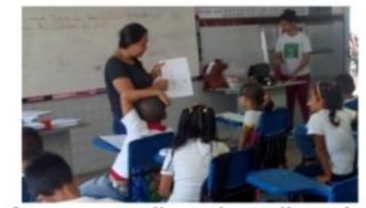

(b) Professora explicando o diagnóstico para os alunos

Figura 2. Momentos da aula de diagnóstico inicial da intervenção pedagógica.

\subsection{Aplicação da aula 2 - Apresentação dos recursos e funcionalidades do Software}

Nesta aula, foram apresentados os recursos do Software Luz do Saber. Além disso, foi apresentado aos alunos um vídeo sobre os principais fundamentos do computador.

Neste sentido, para esta aula foram definidos: R.P.A. 01 - Compreenda os recursos e funcionalidades do software Luz do Saber, A. E. 02 - Apresentar os recursos e funcionalidades Luz do Saber, A. E. 03 - Propor exercício de fixação sobre os recursos e funcionalidade do software Luz do Saber, A. A. 02 - Assistir à apresentação sobre os recursos e funcionalidades do software Luz do Saber e A. A. 03 - Desenvolver o exercício de fixação sobre os recursos e funcionalidades do software Luz do Saber.

Por fim, os alunos desenvolveram um exercício prático de adaptação com os recursos e funcionalidades do software Luz do Saber. Na figura 3a é possível observar a professora explica as atividades da etapa aprendendo a usar o computador no software Luz do Saber. Na figura 3b é apresentado os alunos desenvolvendo um exercício de adaptação. De modo geral, as atividades propostas para esta aula foram concluídas em 40 minutos.

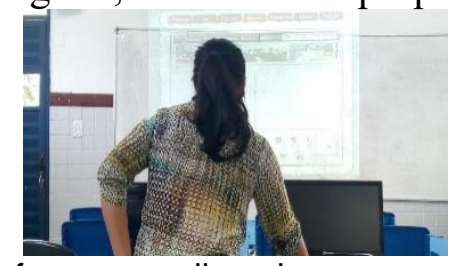

(a) Professora explicando os recursos e funcionalidades

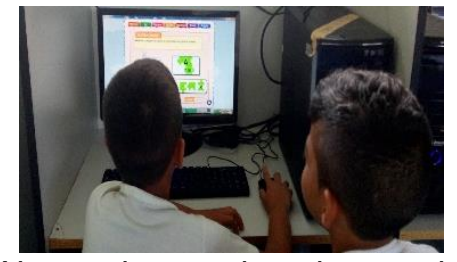

(b) Alunos desenvolvendo exercicio de adaptação com da ferramenta

Figura 3. Momentos da aula de apresentação das ferramentas e recursos do Software.

\subsection{Aplicação da aula 3 - Escrita de uma história em quadrinhos no papel}

Nesta aula, foi proposto o desenvolvimento de uma atividade de criação de história em quadrinho, utilizando lápis e papel.

Neste sentido, para esta aula foram definidos: R.P.A. 02 - Desenvolva habilidades e competências na formação de sílabas, palavras e frases, R.P.A. 03 - Compreenda os fundamentos e os elementos necessários para a criação de histórias em quadrinhos, A. E. 04 - Ler e explicar o roteiro da atividade de desenvolvimento da história em quadrinhos e A. A. 04 - Desenvolver a história em quadrinho proposta.

Incialmente, a professora realizou a explicação do roteiro da atividade e propôs a divisão das duplas para a realização da atividade. Assim, eles deveriam construir um diálogo com base nos personagens de uma história em quadrinhos no papel. No geral, as atividades propostas para esta aula foram executadas em 40 minutos. Nas figuras $4 \mathrm{a}$ e $4 \mathrm{~b}$ é possível observar os alunos desenvolvendo a atividade. 


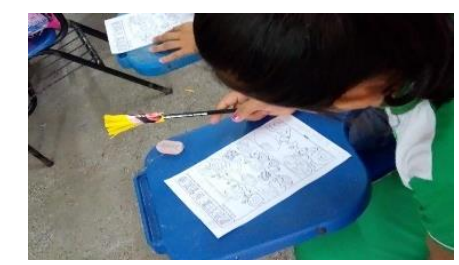

(a) Aluna desenvolvendo construindo a hisória em quadrinho

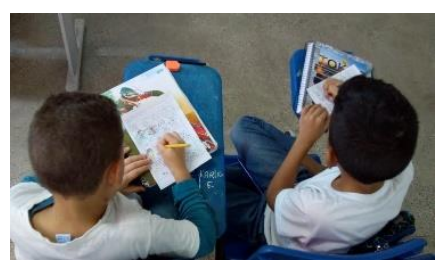

(b) Dupla de alunos desenvolvendo a construção da história em quadrinho

Figura 4. Alunos criando os diálogos da história em quadrinho no papel.

\subsection{Aplicação da aula 4 - Transcrever a história criada no papel para o computador utilizando o software Luz do Saber}

$\mathrm{Na}$ quarta aula, foi realizada uma atividade de transcrição da história em quadrinho para o software Luz do Saber utilizando a sessão Gibi.

Para esta aula foram definidos: R.P.A. 04 - Compreenda e utilize os recursos e funcionalidades do software Luz do Saber para transcrever a história em quadrinho, A. E. 05 - Ler e explicar o roteiro da atividade de transcrição da história em quadrinhos e A. A. 05 - Desenvolver a atividade de transcrição da história em quadrinhos utilizando o software luz do saber.

As duplas levaram sua história em quadrinhos criada no papel, para realizar a transcrição utilizando o software Luz do Saber na sessão Gibi.

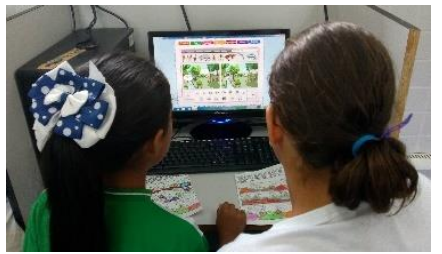

(a) Dupla realizando transcrição da história em quadrinho no computador

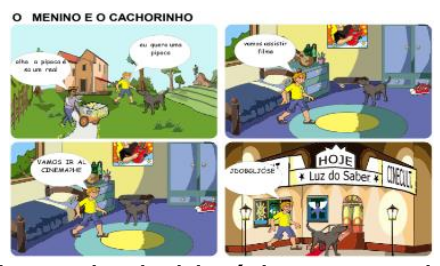

(b) Exemplo de história em quadrinho transcrita com o Luz do Saber

Figura 5. Momentos da aula de transcrição da história em quadrinhos.

\subsection{Aplicação da aula 5 - Diagnóstico final}

Por fim, a última aula tinha como objetivo realizar um diagnóstico final, através de uma roda de conversa para identificar as habilidades e competências desenvolvidas durante a realização das atividades.

Nesta perspectiva, para esta aula foram definidos: A. E. 06 - Ler e explicar o roteiro da roda de conversas de diagnóstico final e A. A. 06 - Participar da roda de conversa de diagnóstico final da intervenção pedagógica.

Inicialmente, a professora propôs um conjunto de perguntas para obter um feedback sobre a intervenção pedagógica, tais como: i - Vocês gostaram das aulas no laboratório?, ii - As atividades desenvolvidas eram difíceis? e iii - As aulas são melhores na sala de aula ou no laboratório de informática? Etc. Além disso, foram realizadas algumas discussões sobre as histórias em quadrinhos produzidas. De modo geral, as atividades desta aula foram conduzidas em 40 minutos. Na figura 6 a é apresentado a professora realizando os questionamentos. Na figura $6 \mathrm{~b}$ os alunos estão participando da roda de conversa do diagnóstico final. 


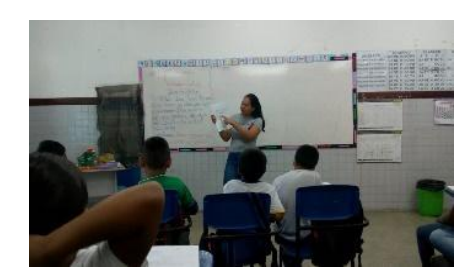

(a) Professora realizando questionamentos sobre as histórias desenvolvidas

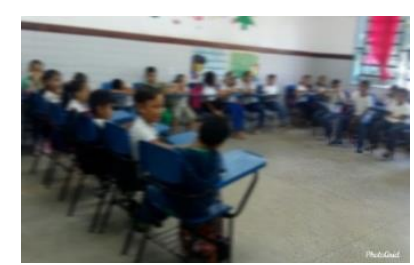

(b) Alunos participando do diagnóstico final na roda de conversa

Figura 6. Momentos da aula de diagnóstico final.

\section{Resultados e Discussões}

De modo geral, apresentamos os resultados sob duas perspectivas. A primeira delas, está diretamente relacionada a participação e envolvimento dos alunos nas atividades da intervenção pedagógica.

Quando perguntados sobre as dificuldades encontradas, 10 deles disseram que suas maiores dificuldades estariam relacionadas ao manuseio do mouse e a escrita utilizando o teclado. Além disso, 17 deles afirmaram que estavam utilizando o computador pela primeira vez. Quando perguntados sobre a sua preferência por trabalhos individuais ou em dupla, todos responderam que "individual" seria mais interessante, porque eles queriam utilizar ao mesmo tempo o computador e ficavam em discordância sobre a atividade a realizar.

No que se refere ao desenvolvimento da leitura e escrita dos alunos através da construção de histórias em quadrinhos, foi possível perceber uma melhora significativa na formação de sílabas simples e complexas, e, formação de frases.

\section{Considerações finais}

Por fim, acreditamos que o desenvolvimento da leitura e escrita por meio da utilização do software Luz do Saber seja uma estratégia viável e factível.

Com base nos resultados, foi possível observar um maior envolvimento, motivação e engajamento dos alunos nas atividades desenvolvidas em sala de aula. Ademais, no que se refere a aprendizagem dos alunos, acreditamos que ao propiciar um ambiente mais criativo e disruptivo, os alunos puderam desenvolver a leitura e a escrita de uma forma mais engajadora, dinâmica e significativa.

Consequentemente, foi possível validar a estratégia proposta neste trabalho. Contudo, acreditamos que ainda exista a necessidade de um maior investimento por parte do poder público na atualização e manutenção dos equipamentos tecnológicos e formação de professores em nossas escolas.

\section{Referências}

Oliveira, M. A. D. C., \& Pereira, I. C. (2013). Atributos esenciales de la Atención Primaria y la Estrategia Salud de la Familia. Revista Brasileira de Enfermagem, 66(SPE), 158164.

Biggs, J. \& Tang, C. (2011). Teaching for Quality Learning at University. Maidenhead, UK: Open University Pressg.

Pazeto, T. D. C. B., León, C. B. R., \& Seabra, A. G. (2017). Avaliação de habilidades preliminares de leitura e escrita no início da alfabetização. Revista Psicopedagogia, 34(104), 137-147. 